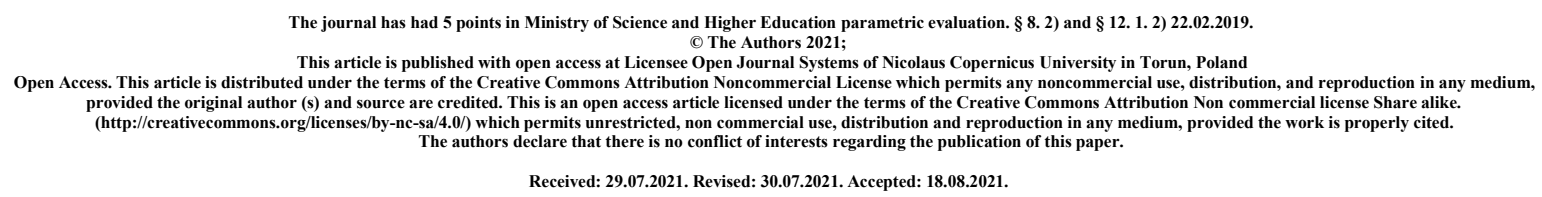

\title{
Comprehensive Rehabilitation After Reconstruction of the Anterior Cruciate Ligament
}

\section{Dawid Besztak}

Affiliation Department of Orthopaedic and Traumatology, Orthopaedic and Traumatology Clinic Pomeranian Medical Medical University, ul. Unii Lubelskiej 1, 71-252 Szczecin

Country Poland

Bio Statement -

\section{Karina Szczypiór-Piasecka}

ORCID iD https://orcid.org/0000-0002-9562-9201

Affiliation Department of Orthopaedic and Traumatology, Orthopaedic and Traumatology Clinic Pomeranian Medical Medical University, ul. Unii Lubelskiej 1, 71-252 Szczecin

Country Poland

Bio Statement -

\section{Alicja Mińko}

ORCID iD https://orcid.org/0000-0003-2299-3958

Affiliation Department of Orthopaedic and Traumatology, Orthopaedic and Traumatology Clinic Pomeranian Medical Medical University, ul. Unii Lubelskiej 1, 71-252 Szczecin

Country Poland

Bio Statement -

Principal contact for editorial correspondence. 


\title{
Krzysztof Antczak
}

ORCID iD https://orcid.org/0000-0001-8443-0611

Affiliation Department of Orthopaedic and Traumatology, Orthopaedic and Traumatology Clinic Pomeranian Medical Medical University, ul. Unii Lubelskiej 1, 71-252 Szczecin

Country Poland

Bio Statement -

\begin{abstract}
Introduction: The knee joint is the second most frequently injured joint. Anterior cruciate ligament (ACL) injury is a relatively common injury to the inner part of the knee joint, mainly related to contact sports. Its rupture leads to instability of the entire joint. Two treatment options are possible: operative or conservative. Each of them is related to an appropriate rehabilitation process. The aim of this study was to define a comprehensive rehabilitation plan in patients after ACL rupture and meniscal suturing.
\end{abstract}

Materials and methods: The work was written based on the medical history of the patient who was diagnosed with complete rupture of ACL, and then reconstruction was performed with the harvesting of a semitendinous and slender muscle graft.

Results: The rehabilitation process can be divided into two stages: hospital and post-hospital. Rehabilitation in hospital conditions begins on the zero day after arthroscopy. The main goals of rehabilitation include: increasing the range of mobility, no myofascial dysfunctions, no thromboembolic complications, and the ability to self-service.

Conclusion: Rehabilitation is an indispensable element of the treatment of patients after ACL reconstruction. Early initiation of rehabilitation brings tangible benefits during treatment and return to full physical fitness.

Key words: ACL; knee; therapy; injuries; reconstruction 


\section{Introduction:}

The knee joint is the second most frequently injured joint (just behind the ankle joint), and the most frequently damaged joint due to sports injuries (about 60\%). Anterior cruciate ligament (ACL) injury is a relatively common injury to the inner part of the knee joint, mainly associated with practicing contact sports such as football, handball, basketball, American football, ice hockey and rugby. ACL is an essential structure of the knee joint, it is responsible for blocking the excessive forward movement of the tibia. Its rupture leads to instability of the entire joint [1-4]. Biomechanically, the ACL is broken during landing, after a jump, deceleration, sudden change of direction or turning with a straight lower limb in the hip and knee joints [5]. Factors influencing the frequency of injuries are: uneven turf surface, weather conditions, inappropriate footwear. About 4-6 times higher risk of an ACL injury is in the female sex. Age is also a risk factor - 15-30 years of age, and with each subsequent year of life the risk of damage to this ligament increases by $1.3 \%[6,7,8]$. ACL rupture may be accompanied by: pain, swelling, instability of the knee joint and damage to adjacent structures, eg medial meniscus, posterior cruciate ligament (PCL), and tibial collateral ligament [9-12]. Popular diagnostic tools in the field of ACL damage are: magnetic resonance imaging (MRI), ultrasound (ultrasound) and x-ray image (X-ray). The following tests are performed in diagnostics without the use of specialized equipment: front drawer test, Lachman test, pivotshift test $[13,14]$.

In ACL injuries, two treatment options are possible: surgical treatment (arthroscopic reconstruction) and continuation - rehabilitation, as well as conservative treatment - intensive physiotherapy aimed at functional improvement of the joint [15]. Nonsurgical treatment is mainly used in partial ACL damage, when the hypermobility associated with anterior instability is negligible. There are also cases of conservative treatment in patients with completely ruptured ACL $[16,17]$. In surgical treatment, there is a division according to the type of graft used for reconstruction: semimembranous (ST) and slender (GR) muscle, patellar ligament and Achilles tendon (currently the least frequently not used) [18, 19, 20]. The decision about the type of treatment is influenced by a number of factors: age, gender, physical activity, comorbidities, profession, financial situation. An inherent element of ACL reconstruction is the implementation of an appropriate rehabilitation process in order to quickly regain fitness. There are many elements used today that make up the rehabilitation process. They include: kinesiotherapy, massage, manual therapy, osteopathy and special methods $[16,21]$. 
The aim of this study was to define a comprehensive rehabilitation plan in patients after ACL rupture and meniscal suturing.

\section{Materials and methods:}

The work was written based on the medical history of a 21-year-old patient who was admitted to the planned ACL reconstruction of the left knee joint at the Surgery Department with the Vascular and Orthopedic Surgery Sub-Department in Szczecin on July 26, 2017. In the first stages of treatment an ultrasound examination was performed, which showed ACL damage. Subsequently, an MRI examination was recommended to determine the degree of damage. Based on the incidence of MR, complete damage to the ACL was found.

The ACL reconstruction procedure was performed on July 27, 2017. During the operation, a slight damage to the medial meniscus of the left knee joint was found. The ST-Gr graft was used from the semi-tendon and slender muscles. Fixing implants (anchors, interference screws, staples) in the femur, tibia and fibula were used. The partially damaged medial meniscus was sutured with FastFix.

The postoperative period was uneventful. The patient was discharged home on July 28 , 2017, in good general condition with the following recommendations: walking with partial load on the operated limb with the protection of elbow crutches for 3 weeks, exercises in the range of knee joint movement 0-90 degrees, especially extension, use of cold compresses of the operated limb (every 2 hours for 15 minutes), changing the dressing daily, sutures to be removed on day 12 at the family doctor, using antithrombotic prophylaxis ( $\mathrm{Rp}$. Clexane 0.04 $1 \mathrm{x} 1 \mathrm{sc}$ for 10 days), orthopedic control in 7 days.

\section{Results:}

The rehabilitation process can be divided into two stages: hospital and post-hospital. Rehabilitation in hospital conditions begins on the zero day after arthroscopy. At this stage of treatment, the main goal is to achieve full extension of the knee joint as quickly as possible. The patient is upright and taught to move on crutches. The goals of inpatient rehabilitation are: increasing the range of mobility, no myofascial dysfunctions, no thromboembolic complications, and the ability to self-serve. The patient is also given self-exercise exercises to help speed up full recovery. In the case of an additionally damaged meniscus, the patient must not put any weight on the fully operated limb for 2-3 weeks after the procedure. Figures 1-5 below present exemplary exercises of this stage of rehabilitation. 


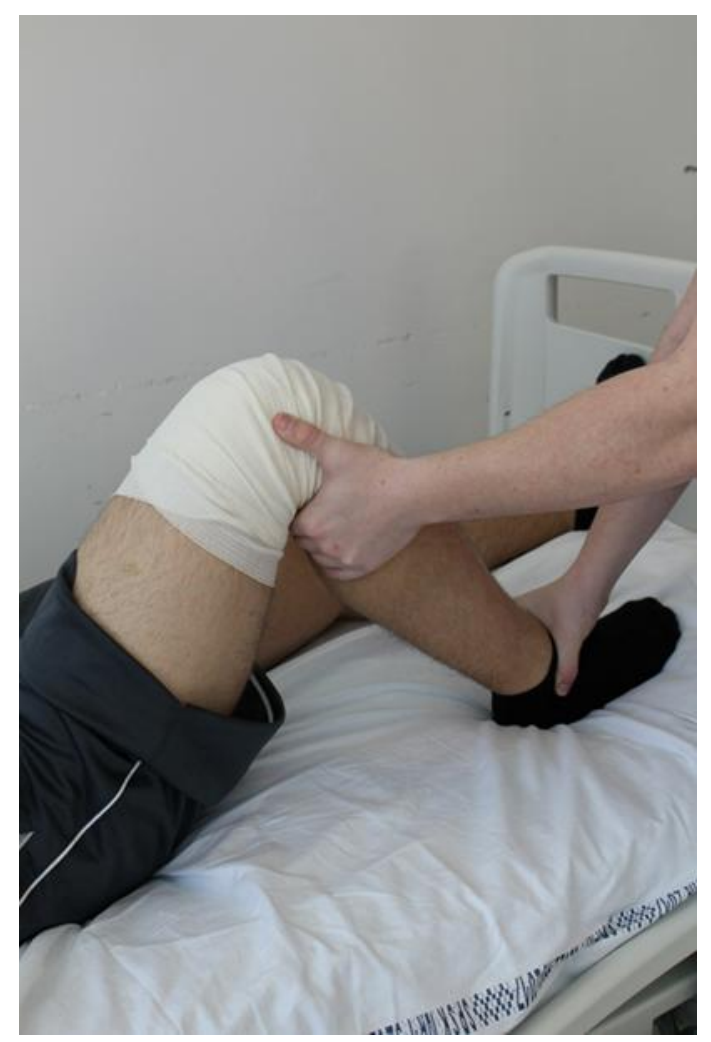

Figure 1. Bend in the knee joint [own source].

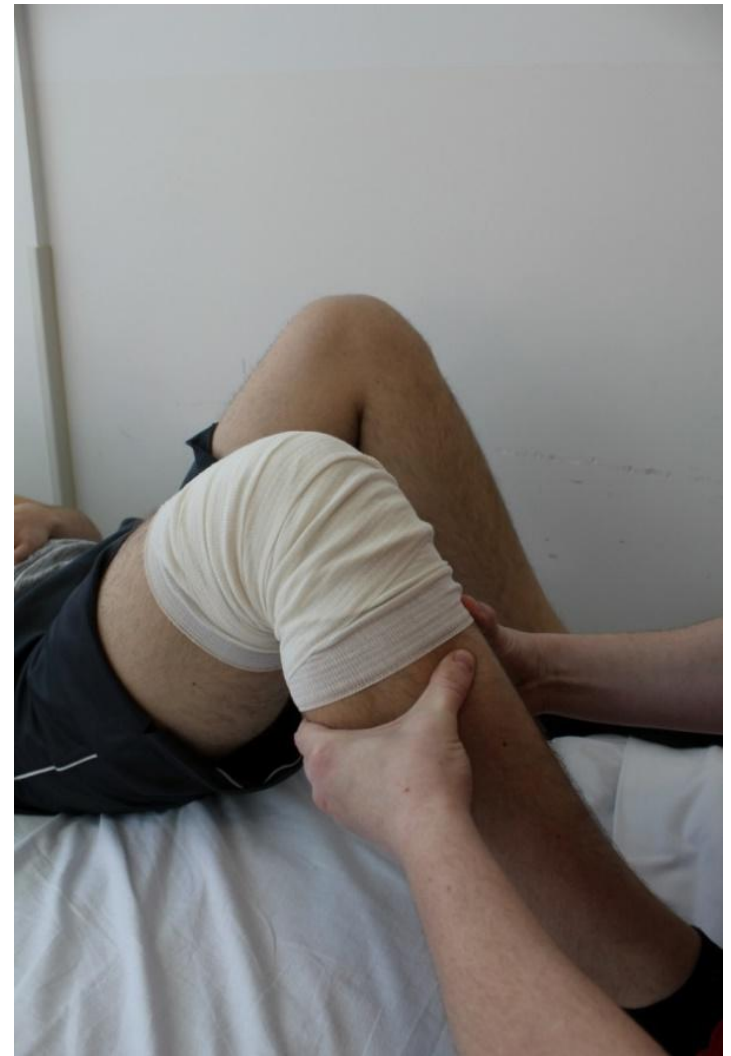

Figure 2. Manual techniques on calf triceps muscle [own source]. 


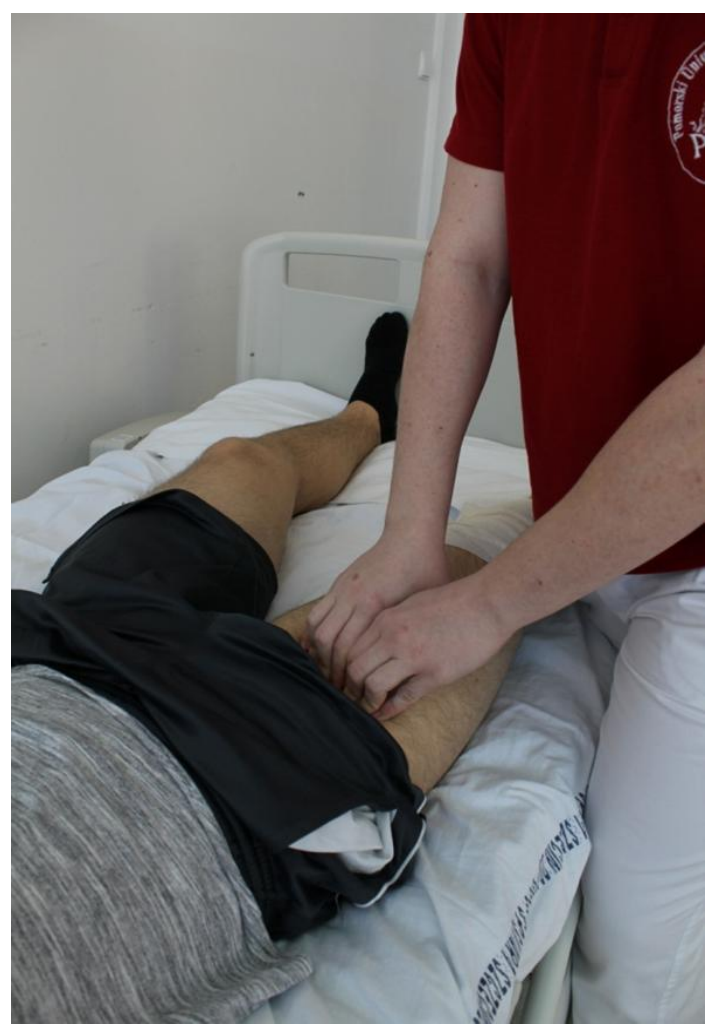

Figure 3. Manual techniques on quadriceps muscle of the thigh [own source].

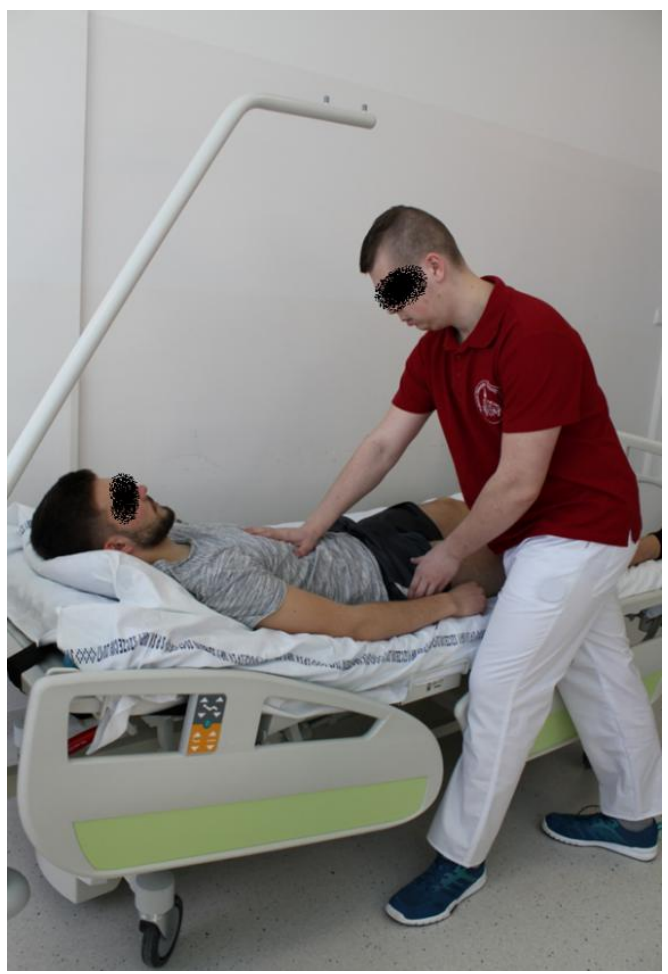

Figure 4. Osteopathy - techniques visceral [own source]. 
In the post-hospital rehabilitation stage, the patient moves independently with full muscle activation. Pain should appear only in the maximum possible flexion for the patient. In addition, it is recommended to work with the scar after the surgery (provided that it is fully healed), as well as with the ACL graft sites (in this case - semi-tendon and slender m.). The muscles of the knee joint should be strengthened and the patient's physical fitness should be increased. Examples of exercises are shown in Figures 5-9.

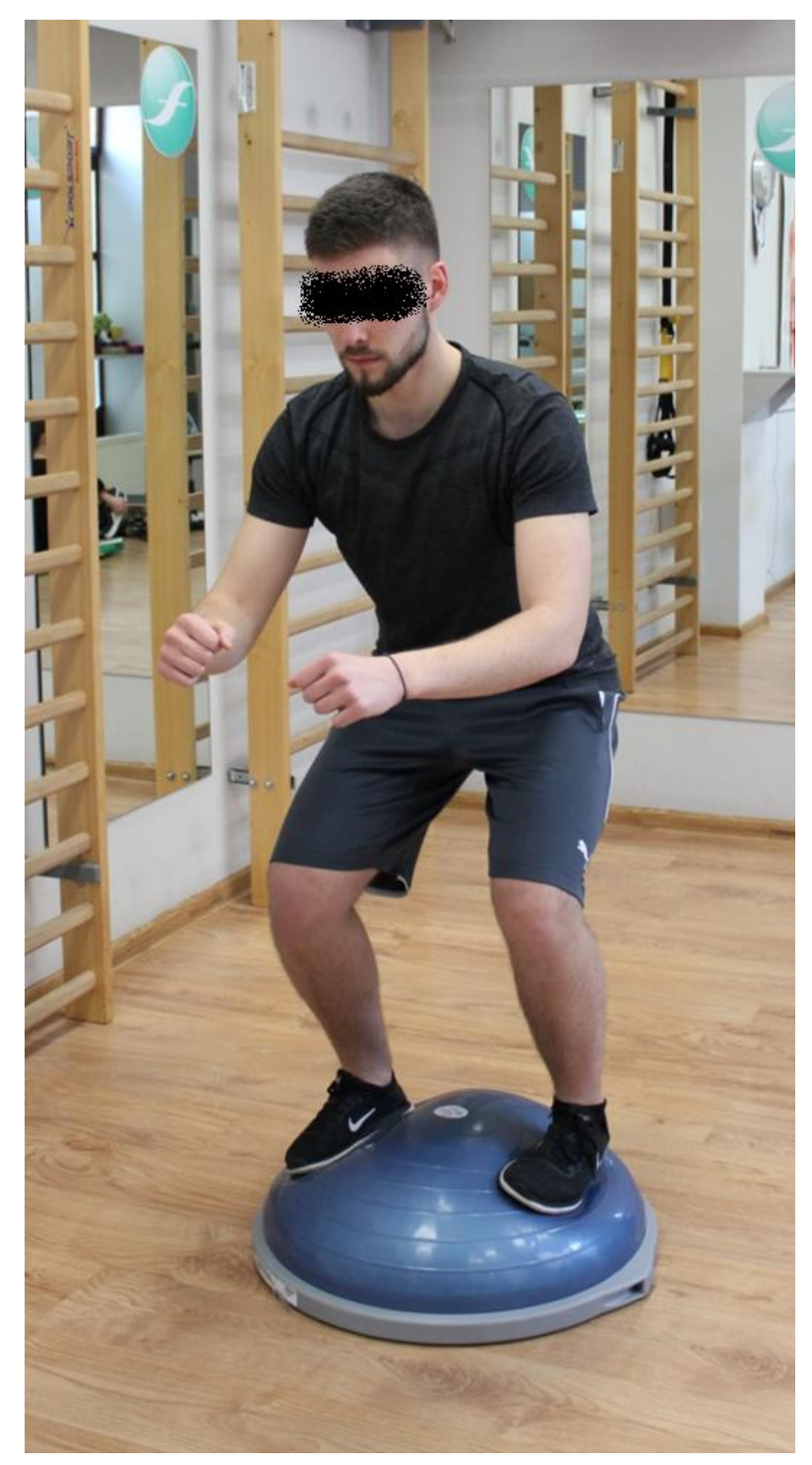

Figure 5. A stabilization exercise on a balancing platform [own source]. 


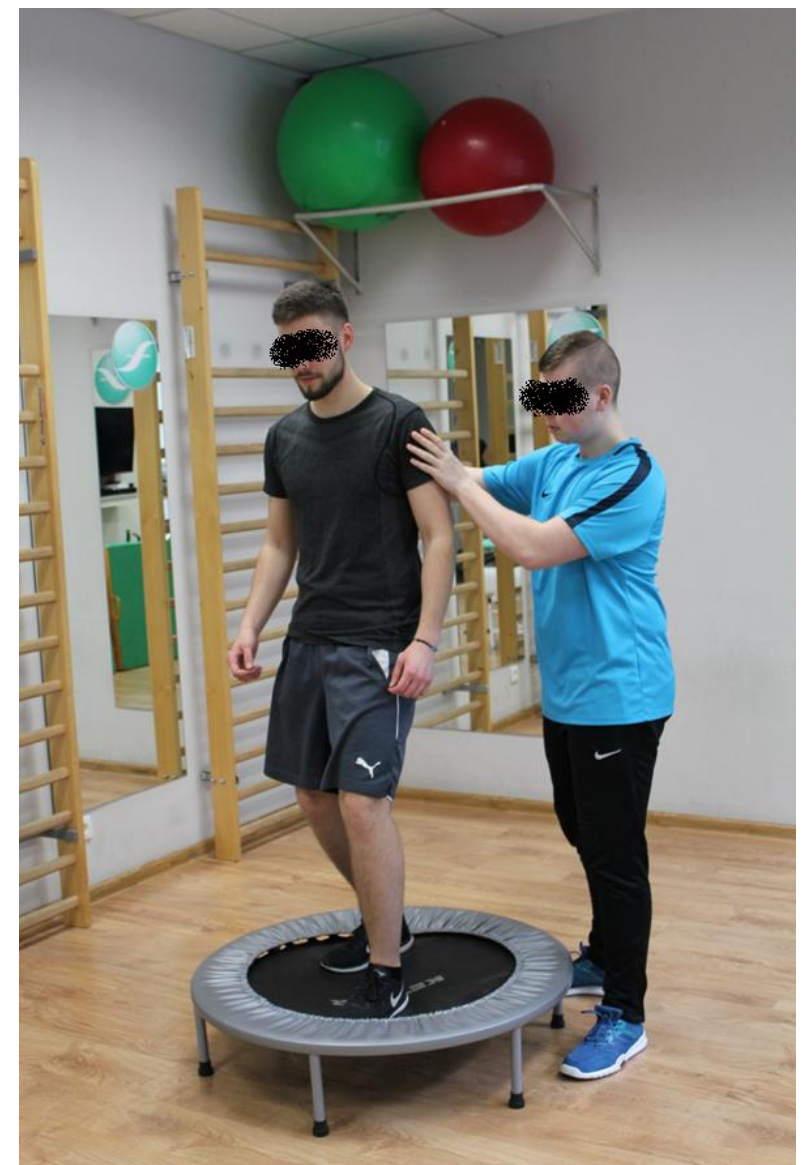

Figure 6. Running on trampolines [own source].

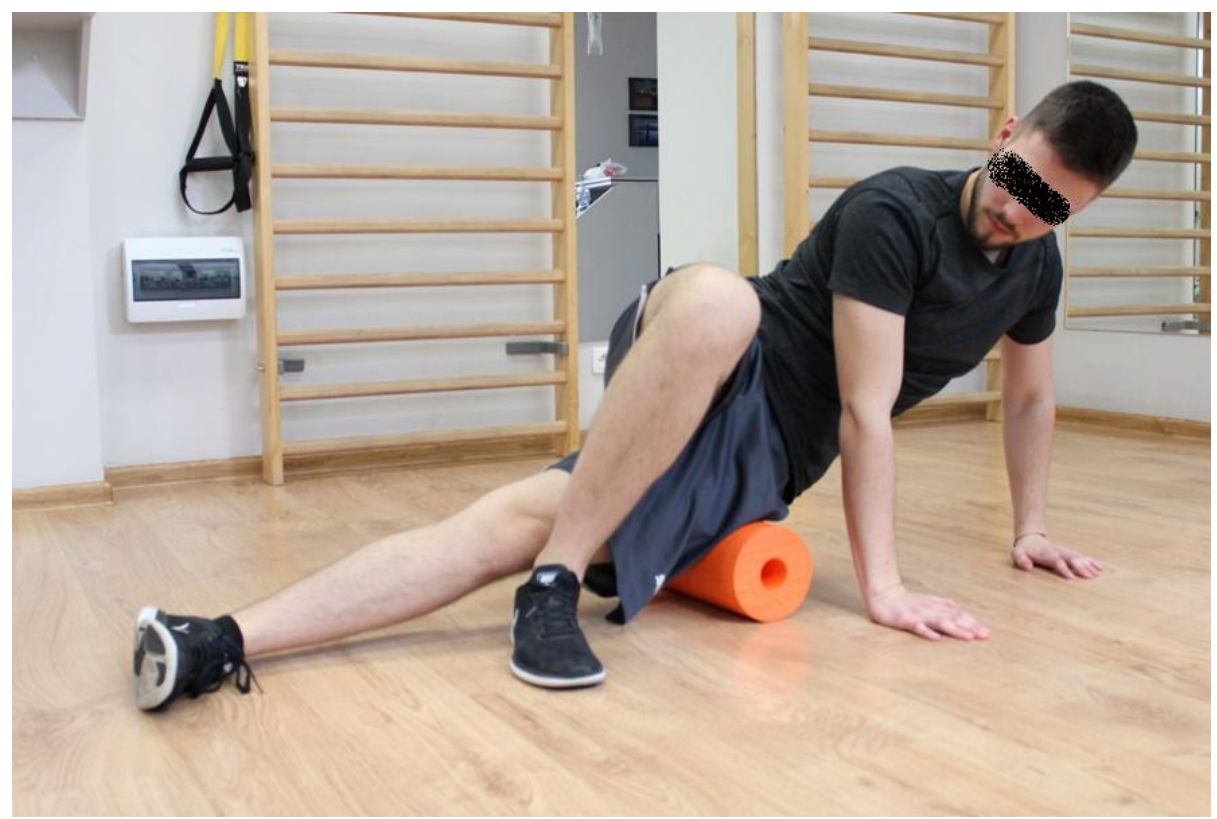

Figure 7. Rolling the side of the thigh [own source]. 


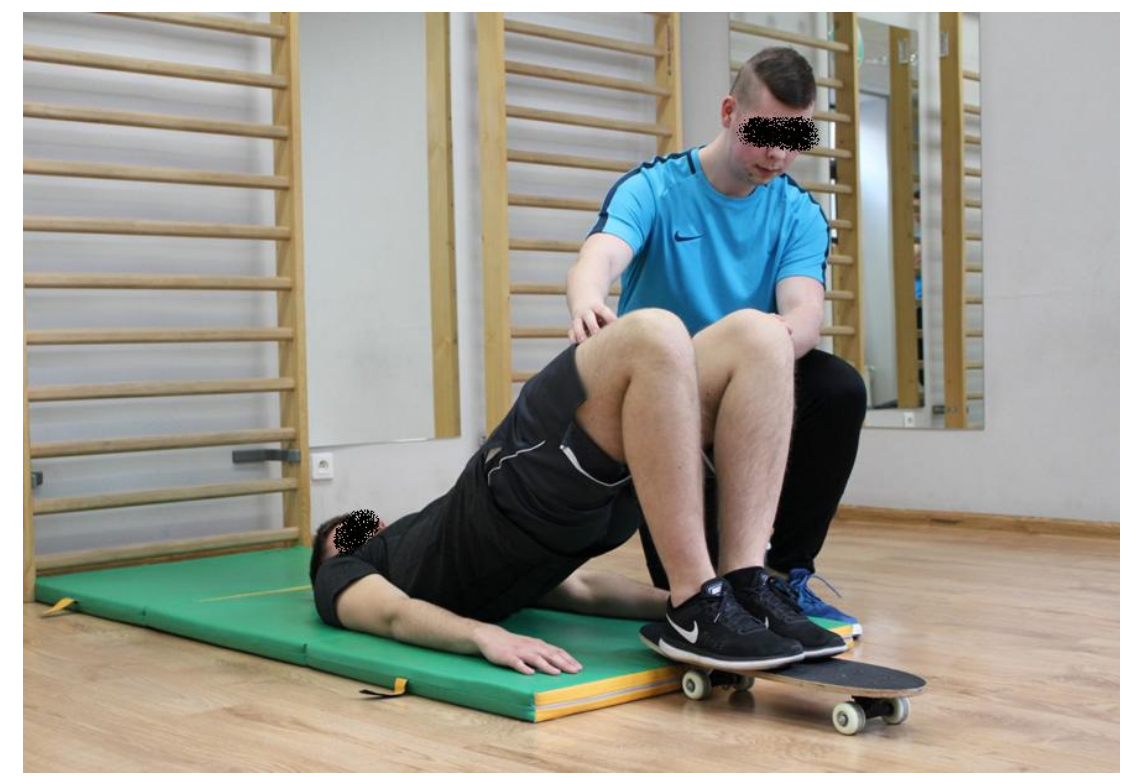

Figure 8. Stabilization exercise on a skateboard [own source].

\section{Discussion:}

ACL repture is a more common knee injury, especially in people who prefer twisting, jumping and direct contact between players. ACL reconstruction restores knee stability, but deficits in muscle strength, neuromuscular control and proprioception may persist for up to 2 years after surgery, therefore comprehensive rehabilitation therapy is an important element in the treatment process [22,23]. The aim of this study was to define a comprehensive rehabilitation plan in patients after ACL reconstruction and meniscal suturing.

According to the literature, in patients who will undergo ACL reconstruction, preoperative rehabilitation is recommended for better postoperative outcomes [24,25]. Rehabilitation should begin as soon as possible and focus mainly on the knee extension and quadriceps strength deficits. In the acute phase, active and passive knee movements are recommended. Cryotherapy may be used as an adjunct to pain management [24].

According to the literature, in the late phase of rehabilitation, neuromuscular training and muscle strength training are recommended. The main goals of this rehabilitation phase are: improving dynamic knee stability and motor control. Evidence-based guidelines recommend both closed kinetic chain and open chain exercise. The late phase of rehabilitation should be individualized to the patient. It should be adapted to the requirements and activity of the patient [24-27]. 


\section{Conclusion:}

Rehabilitation is an indispensable element of the treatment of patients after ACL reconstruction. The introduction of modern techniques, such as manual therapy and osteopathy to rehabilitation, has a positive effect on the effectiveness of therapy. Early initiation of rehabilitation brings tangible benefits during treatment and return to full physical fitness.

\section{Literature:}

1. Ingram JG, Fields SK, Yard EE, Comstock RD. Epidemiology of knee injuries among boys and girls in US high school athletics. Am J Sports Med. 2008;36(6):1116-1122.

2. Harput G, Ulusoy B, Yildiz TI, Demirci S, Eraslan L, Turhan E, Tunay VB. Crosseducation improves quadriceps strength recovery after ACL reconstruction: a randomized controlled trial. Knee Surg Sports Traumatol Arthrosc. 2019 Jan;27(1):68-75. doi: 10.1007/s00167-018-5040-1.

3. Myklebust G, Engebretsen L, Braekken IH, Skjolberg A, Olsen OE, Bahr R. Prevention of anterior cruciate ligament injuries in female team handball players: a prospective intervention study over three seasons. Clin J Sport Med. 2003;13:71-78.

4. Arundale AJH, Capin JJ, Zarzycki R, Smith A, Snyder-Mackler L. Functional and PatientReported Outcomes Improve Over the Course of Rehabilitation: A Secondary Analysis of the ACL-SPORTS Trial. Sports Health. 2018 Sep/Oct;10(5):441-452. doi: $10.1177 / 1941738118779023$.

5. Wong P, Hong Y. Soccer injuries in lower extremities. Br J Sports Med. 2005;39(8):473482 .

6. Myer GD, Ford KR, Hewett TE. The effects of gender on quadriceps muscle activation strategies during a maneuver that mimics a high ACL injury risk position. J. Electromyogr. Kinesiol. 15:181Y189, 2005.

7. Chappell JD, Creighton A, Giuliani C. Kinematics and electro- myographs of landing preparation in vertical stop-jump: risks for noncontact anterior cruciate ligament injury. Am. J. Sports Med. 35:235Y241, 2007.

8. Malinzak RA, Colby SM, Kirkendall DT. A comparison of knee joint motion patterns between men and women in selected athletic tasks. Clin. Biomech. 16:438Y445, 2001.

9. Schulz MS, Russe K, Weiler A, Eichhorn HJ, Strobel MJ. Epidemiology of posterior cruciate ligament injuries. Arch Orthop Trauma Surg 2003; 123: 186-91.

10. Gianotti SM, Marshall SW, Hume PA, Bunt L. Incidence of anterior cruciate ligament injury and other knee ligament injuries: a national population-based study. J Sci Med Sport 2009; 12(6): 622-7.

11. Fleming BC, Hulstyn MJ, Oksendahl HL, Fadale PD. Ligament injury, reconstruction, and osteoarthritis. CurrOpin Orthop. 2005;16(5): 354-62. 
12. Koh J, Dietz J. Osteoarthritis in other joints (hip, elbow, foot, toes, wrist) after sports injuries. Clin Sports Med 2005; 24: 57-70.

13. Grzelak P. Podgórski M. Stefańczyk L. Domżalski M. Nowy ultrasonograficzny test przedniej niestabilności stawu kolanowego - doniesienie wstępne. Journal od Ultrasonography 2014, 14: 252-257.

14. Buckup K. Buckup J. Testy kliniczne w badaniu kości, stawów i mięśni. Wyd. IV. Warszawa: Wydaw. Lekarskie PZWL; 2014. ISBN 978-83-200-4806-3.

15. Adamczyk G. Diagnostyka kliniczna uszkodzeń więzadeł krzyżowych stawu kolanowego. Acta Clinica 2001;1(4); 294-306.

16. Hart C, Bekerom M, Patt T. The occurrence of osteoarthritis at a minimum of ten years after reconstruction of the anterior cruciate ligament. J Orthop Surg Research 2008;3:24-37.

17. Struewer J, Ziring E, Frangen T, Efe T. Clinical outcome and prevalence of osteoarthritis after isolated anterior cruciate ligament reconstruction using hamstring graft: follow-up after two and ten years. Int Orthop 2013; 37:271-277.

18. Nakase J, Kitaoka K, Toratani T, Kosaka M. Grafted tendon healing in femoral and tibial tunnels after anterior cruciate ligament reconstruction. JOrthopSurg 2014;22:65-9.

19. Tow B, Chang P, Mitra A, Tay B. Comparing 2-year outcomes of anterior cruciate ligament reconstruction using either patellatendon or semitendinosus- tendon autografts: A non-randomised prospective study. JOrthopSurg 2005:13:139-146.

20. Kapoor B, Clement D, Kirkley A, Maffulli N. Current practice in the management of anterior cruciate ligament injuries in the United Kingdom.Br J Sports Med 2004;38:542-544.

21. Kochański B, Kałużny K, Dylewska M, Zieliński M. Przygotowanie pacjenta do rekonstrukcji więzadła krzyżowego przedniego (ACL) -opis przypadku. J Health Science 2014;4:173-180.

22. Wright RW, Haas AK, Anderson J, Calabrese G, Cavanaugh J, Hewett TE, Lorring D, McKenzie C, Preston E, Williams G; MOON Group. Anterior Cruciate Ligament Reconstruction Rehabilitation: MOON Guidelines. Sports Health. 2015 May;7(3):239-43. doi: $10.1177 / 1941738113517855$.

23. Wright RW, Preston E, Fleming BC, Amendola A, Andrish JT, Bergfeld JA, Dunn WR, Kaeding C, Kuhn JE, Marx RG, McCarty EC, Parker RC, Spindler KP, Wolcott M, Wolf BR, Williams GN. A systematic review of anterior cruciate ligament reconstruction rehabilitation: part I: continuous passive motion, early weight bearing, postoperative bracing, and homebased rehabilitation. J Knee Surg. 2008 Jul;21(3):217-24. doi: 10.1055/s-0030-1247822.

24. Grindem H., Granan L.P., Risberg M.A., Engebretsen L., Snyder-Mackler L., Eitzen I. How does a combined preoperative and postoperative rehabilitation programme influence the outcome of ACL reconstruction 2 years after surgery? A comparison between patients in the Delaware-Oslo ACL Cohort and the Norwegian National Knee Ligament Registry. Br J Sports Med. 2015;49(6):385-389. 
25. Shaarani S.R., O'Hare C., Quinn A., Moyna N., Moran R., O'Byrne J.M. Effect of prehabilitation on the outcome of anterior cruciate ligament reconstruction. Am J Sports Med. 2013;41(9):2117-2127.

26. Van Melick N., Van Cingel R.E.H., Brooijmans F., Neeter C., Van Tienen T., Hullegie W. Evidence-based clinical practice update: practice guidelines for anterior cruciate ligament rehabilitation based on a systematic review and multidisciplinary consensus. Br J Sports Med. 2016;50(24):1506-1515.

27. Eitzen I., Moksnes H., Snyder-Mackler L., Risberg M.A. A progressive 5-week exercise therapy program leads to significant improvement in knee function early after anterior cruciate ligament injury. J Orthop Sports Phys Ther. 2010;40(11):705-721. 